\title{
The immune system: a target for functional foods?
}

\author{
Philip C. Calder* and Samantha Kew \\ Institute of Human Nutrition, School of Medicine, University of Southampton, Bassett Crescent East, \\ Southampton SO16 7PX, UK
}

\begin{abstract}
The immune system acts to protect the host from infectious agents that exist in the environment (bacteria, viruses, fungi, parasites) and from other noxious insults. The immune system is constantly active, acting to discriminate 'non-self' from 'self'. The immune system has two functional divisions: the innate and the acquired. Both components involve various bloodborne factors (complement, antibodies, cytokines) and cells. A number of methodologies exist to assess aspects of immune function; many of these rely upon studying cells in culture ex vivo. There are large inter-individual variations in many immune functions even among the healthy. Genetics, age, gender, smoking habits, habitual levels of exercise, alcohol consumption, diet, stage in the female menstrual cycle, stress, history of infections and vaccinations, and early life experiences are likely to be important contributors to the observed variation. While it is clear that individuals with immune responses significantly below 'normal' are more susceptible to infectious agents and exhibit increased infectious morbidity and mortality, it is not clear how the variation in immune function among healthy individuals relates to variation in susceptibility to infection. Nutrient status is an important factor contributing to immune competence: undernutrition impairs the immune system, suppressing immune functions that are fundamental to host protection. Undernutrition leading to impairment of immune function can be due to insufficient intake of energy and macronutrients and/or due to deficiencies in specific micronutrients. Often these occur in combination. Nutrients that have been demonstrated (in either animal or human studies) to be required for the immune system to function efficiently include essential amino acids, the essential fatty acid linoleic acid, vitamin $\mathrm{A}$, folic acid, vitamin $\mathrm{B}_{6}$, vitamin $\mathrm{B}_{12}$, vitamin $\mathrm{C}$, vitamin $\mathrm{E}, \mathrm{Zn}, \mathrm{Cu}, \mathrm{Fe}$ and Se. Practically all forms of immunity may be affected by deficiencies in one or more of these nutrients. Animal and human studies have demonstrated that adding the deficient nutrient back to the diet can restore immune function and resistance to infection. Among the nutrients studied most in this regard are vitamin $\mathrm{E}$ and $\mathrm{Zn}$. Increasing intakes of some nutrients above habitual and recommended levels can enhance some aspects of immune function. However, excess amounts of some nutrients also impair immune function. There is increasing evidence that probiotic bacteria improve host immune function. The effect of enhancing immune function on host resistance to infection in healthy individuals is not clear.
\end{abstract}

Nutrition: Immune function: Lymphocyte: Macrophage: Monocyte: Cytokine: Infection

\section{The immune system}

\section{Introduction}

The immune system acts to protect the host from infectious agents that exist in the environment (bacteria, viruses, fungi, parasites) and from other noxious insults. The immune system is constantly active, acting to discriminate 'non-self' from 'self'. The immune system has two functional divisions: the innate (or natural) immune system and the acquired (also termed specific or adaptive) immune system. Both components of immunity involve various blood-borne factors (complement, antibodies, cytokines) and cells. These cells are generally termed leucocytes (or white blood cells). Leucocytes fall into two broad categories: phagocytes (which include granulocytes (neutrophils, basophils, eosinophils), monocytes and macrophages) and lymphocytes. Lymphocytes are classified as T lymphocytes, B lymphocytes and natural killer cells. $\mathrm{T}$ lymphocytes are further divided into helper $\mathrm{T}$ cells (these are distinguished by the presence of the

\footnotetext{
Abbreviations: DTH, delayed-type hypersensitivity; IFN- $\gamma$, interferon- $\gamma$; Ig, immunoglobulin; IL, interleukin; MHC, histocompatibility complex; TNF, tumour necrosis factor.

* Corresponding author: Dr P. C. Calder, fax +44 238059 4383, email pcc@ soton.ac.uk
} 
molecule CD4 on their surface) and cytotoxic T cells (these are distinguished by the presence of CD8 on their surface). All cells of the immune system originate in bone marrow. They are found circulating in the bloodstream, organised into lymphoid organs such as the thymus, spleen, lymph nodes and gut-associated lymphoid tissue, or dispersed in other locations around the body.

\section{Innate and acquired immunity}

Innate immunity is the first line of defence against infectious agents. It is present prior to exposure to pathogens and its activity is not enhanced by such exposures. Innate immunity is concerned with preventing entry of infectious agents into the body and, if they do enter, with their rapid elimination. Elimination can occur by:

1. direct destruction of pathogens by complement, by toxic chemicals (e.g. superoxide radicals and hydrogen peroxide) released by phagocytes or by toxic proteins released by natural killer cells;

2. engulfing pathogens by the process of phagocytosis, which is made more efficient by coating the invading pathogen with host proteins like complement or antibodies, and their subsequent destruction.

Acquired immunity involves the specific recognition of molecules (antigens) on an invading pathogen, which distinguish it as being foreign to the host. The recognition of antigens is by antibodies (immunoglobulins (Ig) produced by $\mathrm{B}$ lymphocytes) and by $\mathrm{T}$ lymphocytes. $\mathrm{T}$ lymphocytes are only able to recognise antigens displayed on cell surfaces. Therefore, infection of a cell by an intracellular pathogen is signalled to $\mathrm{T}$ lymphocytes by cell surface expression of peptide fragments derived from the pathogen. These fragments are transported to the surface of the infected cell and expressed there in conjunction with proteins termed major histocompatibility complex (MHC); in man MHC is termed human leucocyte antigen. It is the combination of the pathogen-derived peptide fragment bound to MHC that is recognised by $\mathrm{T}$ lymphocytes. There are two classes of MHC, MHC I and MHC II, and the source of the peptide bound to each differs. MHC I binds peptides that originate from pathogen proteins synthesised within the host cell cytosol; typically these are from viruses or certain bacteria. The peptides bound to MHC II are derived from pathogens that have been phagocytosed by macrophages or endocytosed by antigen-presenting cells (macrophages, dendritic cells, B lymphocytes). The MHC-peptide complex is recognised by the $\mathrm{T}$ cell receptor on $\mathrm{T}$ lymphocytes. $\mathrm{T}$ lymphocytes expressing CD8 recognise MHC I, while T lymphocytes expressing CD4 recognise MHC II. Thus, intracellular pathogens stimulate cytotoxic $\mathrm{T}$ lymphocytes to destroy the infected cell, while extracellular pathogens stimulate a helper $\mathrm{T}$ cell-mediated response.

The acquired immune system includes a component of memory, such that if the antigen is encountered again (i.e. there is re-infection) the response is faster and stronger than the initial response. Although the immune system as a whole can recognise tens of thousands of antigens, each lymphocyte can recognise only one antigen and so the number of lymphocytes specific for a particular antigen must be very low. However, when an antigen is encountered it binds to the small number of lymphocytes that recognise it and causes them to divide so as to increase the number of cells capable of mounting a response to the antigen; this is the process termed lymphocyte expansion or proliferation. B lymphocytes proliferate and mature into antibody-producing cells (plasma cells) and $\mathrm{T}$ lymphocytes proliferate and are able directly to destroy virally infected cells (cytotoxic T lymphocytes) or control the activity of other cells involved in the response (helper $\mathrm{T}$ cells). The B lymphocyte response to antigen is termed humoral immunity and the $\mathrm{T}$ cell response is termed cell-mediated immunity.

\section{Integration of the immune response}

Communication within the acquired immune system and between the innate and acquired systems is brought about by direct cell-to-cell contact involving adhesion molecules and by the production of chemical messengers. Chief among these chemical messengers are proteins called cytokines, which can act to regulate the activity of the cell that produced the cytokine and/or of other cells. Each cytokine can have multiple activities on different cell types. Cytokines act by binding to specific receptors on the cell surface and thereby induce changes in growth, development or activity of the target cell.

When an immunological stimulus is encountered, the innate response, including its inflammatory component, responds initially, acting directly to eliminate it by the activities of complement, phagocytosis, etc. Cytokines (e.g. tumour necrosis factor- $\alpha$ (TNF- $\alpha)$, interleukin (IL)-1 and IL-6) produced by the cells involved in the innate response, especially monocytes and macrophages, will regulate this response and also act systemically on the liver to promote acute phase protein synthesis, on skeletal muscle and adipose tissue to promote proteolysis and lipolysis, respectively (this is believed to be the body's way of providing fuels to the immune system) and on the brain to reduce appetite and induce fever. These cytokines will also interact with $\mathrm{T}$ lymphocytes. Antigen-presenting cells, which include activated monocytes and macrophages, will present antigen to $\mathrm{T}$ lymphocytes and so the acquired immune response will be triggered. Now there will be a cell-mediated response to the antigen. T lymphocytes will produce cytokines which will regulate the activity of the cells involved in the innate response (monocytes, macrophages, natural killer cells), promote the proliferation of $\mathrm{B}$ and $\mathrm{T}$ lymphocytes and promote antibody production by B lymphocytes. By virtue of the integrated innate and acquired responses the source of the antigen should be eliminated and a component of immunological memory will remain (Fig. 1).

\section{Biomarkers of immune function}

There is a wide range of methodologies by which to assess the immune response and the impact of nutrient supply on immune function (for a discussion see CunninghamRundles, 1998). Assessments can be made of cell functions 
ex vivo (i.e. of the isolated cells outside the body and studied in short- or long-term culture), of indicators of immune function in vivo (e.g. by measuring the concentrations of proteins relevant to immune function in the bloodstream), of responses to an immunological challenge (e.g. inoculation with an antigen, a vaccine or live bacteria) or, in human studies, of the incidence and severity of infectious diseases. Clearly, animals offer greater access to the immune system, but it is important that observations made in animal studies be confirmed in man. Although ex vivo measures of immune function are made frequently, changes in these may not necessarily result in an altered immune response in vivo. Thus, in order to ascertain the effect of an intervention on the immune response, measures reflecting in vivo activity of the immune system are superior to ex vivo measures. However, the two approaches should be used in combination to understand better the mechanism of impact of an intervention.

\section{Ex vivo measures}

Animal studies often investigate the functions of immune cells isolated from the blood, thymus, spleen, lymph nodes, peritoneal cavity and, in some cases, from the bone marrow, lungs, liver and gastrointestinal tract. Human studies are more limited and routinely only the blood pool is sampled. In some cases other sources of human immune cells have been studied: for example, studies of asthma and respiratory illness often use cells collected by bronchoalveolar lavage. Measures of immune function that can be made on cells cultured ex vivo include:

1. Phagocytosis of bacteria, sheep red blood cells or yeast particles by neutrophils, monocytes and macrophages; this can be coupled with measures of bacterial killing.

2. Respiratory burst (superoxide generation) by neutrophils, monocytes and macrophages in response to

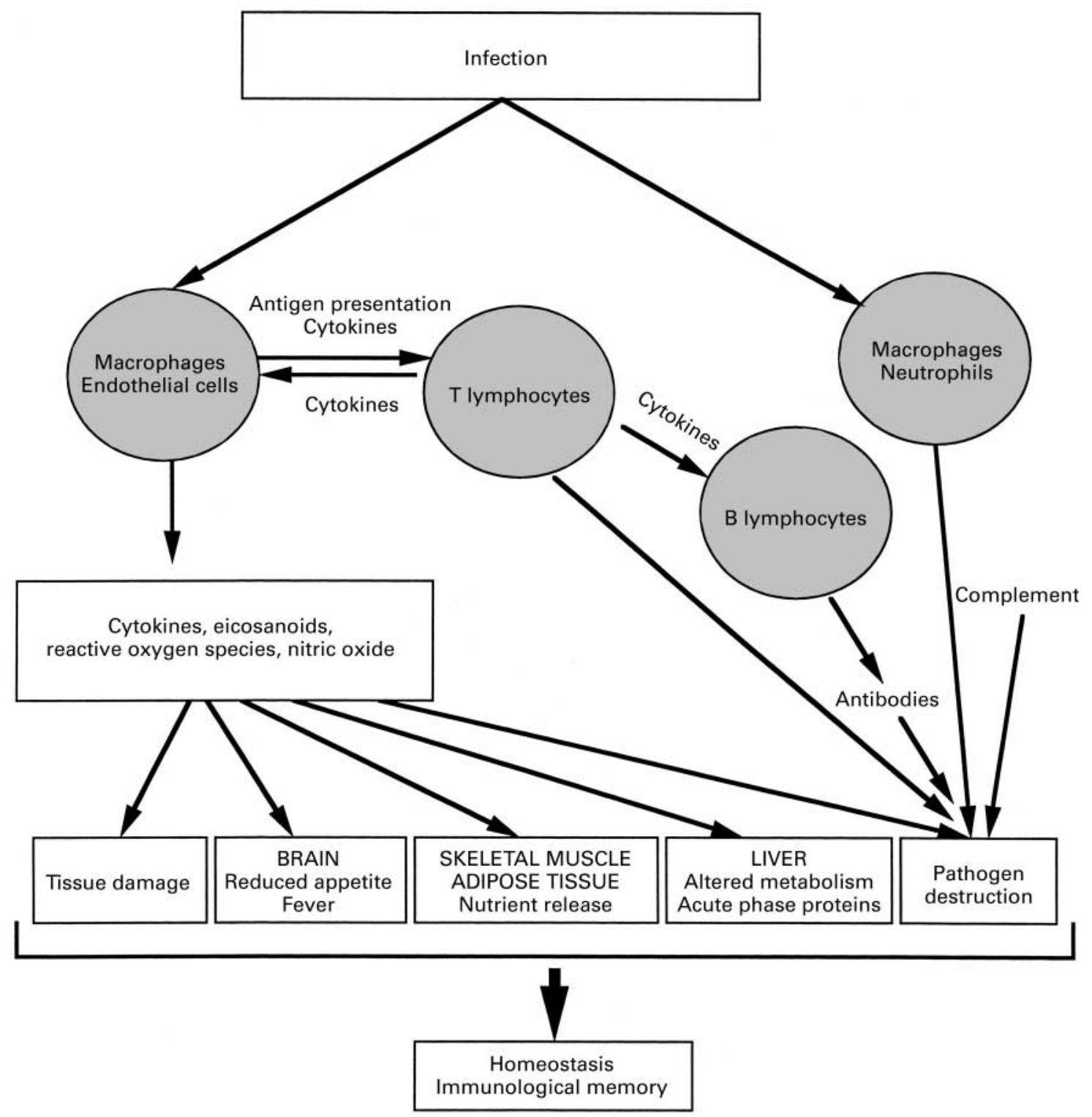

Fig. 1. Integration of the immune response. 
bacteria or bacterial peptides; this can be coupled with measures of bacterial killing.

3. Natural killer cell activity, measured as killing of tumour cells known to be specific targets for natural killer cells.

4. Cytotoxic T lymphocyte activity, measured as killing of virally infected cells known to be specific targets for cytotoxic $\mathrm{T}$ cells.

5. Lymphocyte proliferation. This is the increase in number of lymphocytes in response to a stimulus. Most often this is measured as the incorporation of radioactively labelled thymidine into the DNA of the dividing lymphocytes, although a number of other measures are available. Agents used to stimulate lymphocyte proliferation include concanavalin $\mathrm{A}$ and phytohaemagglutinin, which stimulate T lymphocytes. These agents are all known as mitogens and the process as mitogen-stimulated lymphocyte proliferation. If the individual has been sensitised to an antigen (or allergen), then the antigen can be used to stimulate lymphocyte proliferation.

6. Production of cytokines by lymphocytes, monocytes and macrophages. This usually requires the cells to be stimulated. For lymphocytes, mitogens (or antigens, if the individual has been sensitised) are used, while for monocytes and macrophages bacterial lipopolysaccharide is most often used.

7. Production of total or specific Ig by lymphocytes.

8. Cell surface expression of molecules involved in antigen presentation (e.g. MHC) and in cellular activation (e.g. cytokine receptors).

\section{In vivo measures}

Measures of immune function that reflect in vivo activity include:

1. Size of lymphoid organs.

2. Cellularity of lymphoid organs.

3. Number and types of immune cells circulating in the bloodstream.

4. Cell surface expression of molecules involved in antigen presentation (e.g. MHC) and in cellular activation (e.g. cytokine receptors).

5. Circulating concentration of thymulin and its activity.

6. Circulating concentrations of total Ig and of the Ig subclasses.

7. Circulating concentrations of Ig specific for antigens after an antigen challenge.

8. Concentration of secretory $\operatorname{IgA}$ in saliva, tears and intestinal washings.

9. Circulating concentrations of cytokines.

10. Delayed-type hypersensitivity (DTH) response to intradermal application of an antigen to which the individual has already been exposed; this measures the cell-mediated immune response. The response is measured as the size of the swelling (termed induration) around the area of application at a period (usually forty-eight hours) after the application.

11. Resistance to challenge with live pathogens; the outcome is usually survival, although this can be coupled with some of the above measures and with measures of the numbers of pathogens found in various organs (e.g. spleen, lymph nodes, liver). This has been used in animal experiments.

12. Incidence and severity of infectious diseases. This has been used in some human studies to suggest interactions between nutrient status and immune function.

\section{In vitro studies}

In addition to the above approaches, which can be used to assess the impact of a nutrient supplied in the diet on immune function, in vitro studies adding the nutrient in pure form directly to immune cells in culture can be used. Each of the cell functions listed above under 'ex vivo measures' can be studied in this way. In vitro studies use conditions that are highly controlled, although they are often rather unphysiological in nature. For example, the cells are cultured in isolation from the other types of cell that they would come into contact with in the body (this is also a problem with many ex vivo measures) and the concentrations of the pure nutrient added to the cultures are often greatly in excess of those that can be attained in vivo. Also, the exact form of the nutrient added directly to cell cultures might be different from the form that is available to the cells in vivo. Nevertheless, in vitro studies are useful to identify the potential effects of dietary components and to study their mechanisms of action. However, it is necessary that effects identified in in vitro studies be confirmed in controlled dietary studies.

\section{There is significant inter-individual variation in immune biomarkers}

Variation in cellular immune responses among individuals is not a great problem in animal studies since these most often use inbred strains. However, it is important to note that some responses do differ among animal species and even among different strains within a species. It is possible that immune cells from different species and strains will exhibit different sensitivities to the amount of a nutrient in the diet. Thus, extrapolations from animal studies to man should be made cautiously. There is wide variation in immune cell responses among healthy human subjects (Table 1; see also Yaqoob et al. 1999), and immune responses can be affected by the presence of disease. Individuals with deficient immune responses are more susceptible to infectious agents and suffer greater morbidity and mortality as a result of infections. Such individuals have one or more key immune responses that fall below the threshold that represents 'normality'. However, it is not at all clear whether variation in immune responses within the 'normal' range results in variable susceptibility to infection. Understanding the relationship between the variations in immune responses and in susceptibility to infection is complicated by a number of other factors. For example, vaccination is widely used to prime the immune system to efficiently eliminate certain pathogens that may or may not exist in the environment at some later stage, antibiotics are used widely to help the host 
eliminate pathogens once infection takes hold, and populations (at least in developed countries) exist in increasingly hygienic (i.e. pathogen-free) environments. Nevertheless, studies in the developing world demonstrate that strategies which improve immune function in populations with impaired immunity do lower the incidence and severity of some infections in at-risk groups (Calder \& Jackson, 2000). Despite this most important observation, it does not necessarily follow that increasing immune function per se will improve host resistance, and individuals with functions in the 'normal' range may not benefit from increased immune function. In other words, increasing the activity of one or more components of the immune system (as tested by the above methodologies) may not necessarily be of any benefit to the individual, just as decreasing the activity of one or more components of the immune system (as tested by the above methodologies) may not be detrimental to the individual.

The wide variation in any given immune response among individuals is in part related to genetic polymorphisms, which regulate the expression of cytokines, cytokine receptors, human leucocyte antigen, adhesion molecules and so on. However, other factors such as age, gender, smoking habits, habitual levels of exercise, alcohol consumption, diet, stage in the female menstrual cycle, stress, and history of infections and vaccinations are likely to be important contributors to the observed variation (Fig. 2). Some studies suggest that the prenatal and early life environments can affect later immune competence (Beach et al. 1982; Calder \& Yaqoob, 2000), resistance to infections (Moore et al. 1997; Rayon et al. 1997) and response to vaccination (McDade et al. 2001). Consideration of the variation in immune response among individuals is important when designing and interpreting human studies. It is not clear whether there is variation in responsiveness of the human immune system to the effects of nutrients, although some studies suggest that this varies with age (e.g. Meydani et al. 1991).

\section{Nutrition and immune function}

\section{General}

Undernutrition impairs the immune system, suppressing immune functions that are fundamental to host protection against pathogenic organisms. Undernutrition leading to impairment of immune function can be due to insufficient intakes of energy and macronutrients and/or due to deficiencies in specific micronutrients (vitamins and minerals). Often these occur in combination. Clearly the impact of undernutrition is greatest in developing countries, but it is also important in developed countries especially amongst the elderly, individuals with eating disorders, alcoholics, patients with certain diseases, and premature and small-for-gestational-age babies. Many studies of the interaction between nutrient availability and immune function have been performed in animals and these have often compared the effects of diets containing insufficient, sufficient and, in some cases, excess amounts of an individual nutrient under study. Such studies are valuable because they allow the effect 


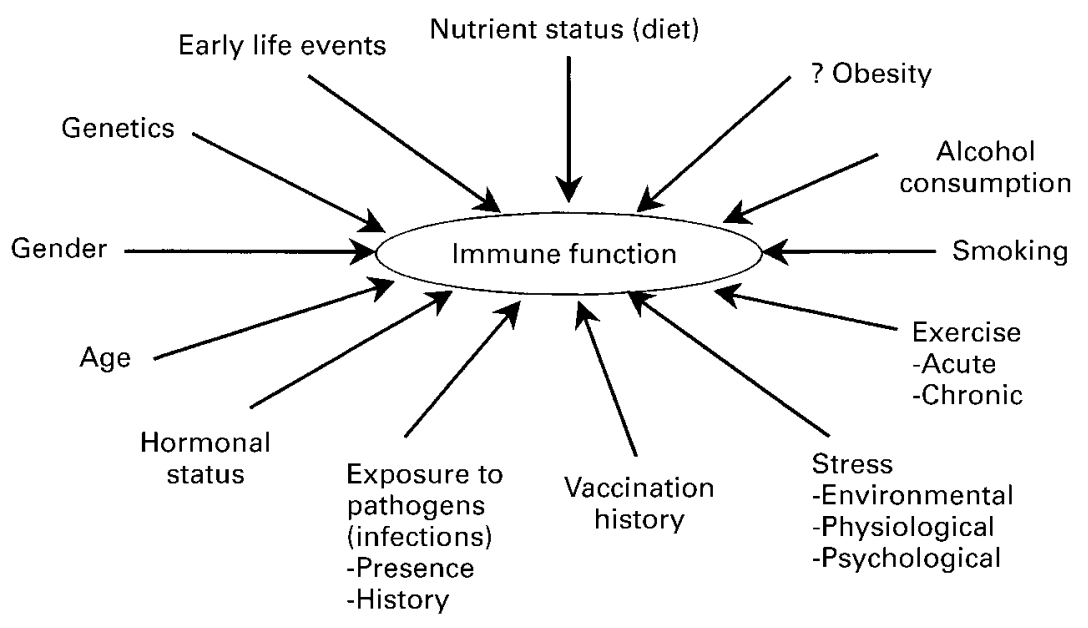

Fig. 2. Sources of variation in immune function.

of the nutrient to be studied in a highly controlled setting, and because the immune system of experimental animals is more accessible than that of man. In man, studies of the immunological impact of nutrient deficiencies have been imposed by habitual consumption of diets deficient in one or more nutrients, or, more rarely, through individuals with diseases that result in inability to absorb nutrients. These studies have made it clear that there are a number of nutrients whose availability at an appropriate level is essential if the immune response is to operate efficiently. Nutrients that have been demonstrated (in either animal or human studies) to be required for the immune system to function efficiently include essential amino acids, the essential fatty acid linoleic acid, vitamin A, folic acid, vitamin $\mathrm{B}_{6}$, vitamin $\mathrm{B}_{12}$, vitamin $\mathrm{C}$, vitamin $\mathrm{E}, \mathrm{Zn}, \mathrm{Cu}, \mathrm{Fe}$ and Se (for reviews see Gross \& Newberne, 1980; Chandra, 1991; Kuvibidila et al. 1993; Scrimshaw \& SanGiovanni, 1997; Calder \& Jackson, 2000). Practically all forms of immunity may be affected by deficiencies in one or more of these nutrients and the deficient animal or individual becomes more susceptible to infections. Animal and human studies have demonstrated that adding the deficient nutrient back to the diet can restore immune function and resistance to infection (for reviews see Chandra, 1991; Scrimshaw \& SanGiovanni, 1997; Calder \& Jackson, 2000).

Vitamin E and zinc: well researched examples of the impact of the dietary supply of micronutrients on immune function

Vitamin E. Vitamin E is the major lipid-soluble antioxidant in the body and is required for protection of membrane lipids from peroxidation. Since free radicals and lipid peroxidation are immunosuppressive, it is considered that vitamin $\mathrm{E}$ should act to optimise and even 'enhance' the immune response (for reviews see Bendich, 1993; Meydani \& Beharka, 1998). In laboratory animals, vitamin E deficiency decreased spleen lymphocyte proliferation, natural killer cell activity, specific antibody production following vaccination, and phagocytosis by neutrophils (for reviews see Bendich, 1993; Meydani \&
Beharka, 1998). The effects of vitamin $\mathrm{E}$ depletion are more marked if animals are fed a diet containing a high level of polyunsaturated fatty acids (Corwin \& Schloss, 1980). Vitamin E deficiency increases susceptibility of animals to infectious pathogens (for references see Meydani \& Beharka, 1998). Vitamin E supplementation of the diet of laboratory animals enhances antibody production, lymphocyte proliferation, natural killer cell activity, and macrophage phagocytosis (for references see Meydani \& Beharka, 1998). Adding vitamin E to the diet of aged mice increased lymphocyte proliferation, IL-2 production and the DTH response (Meydani et al. 1986). A high level of vitamin $\mathrm{E}$ in the diet $(500 \mathrm{mg} / \mathrm{kg}$ food) also increased natural killer cell activity of spleen cells from old, but not young, mice (Meydani et al. 1988). Dietary vitamin E promotes resistance to pathogens in chickens, turkeys, mice, pigs, sheep and cattle (for references see Meydani \& Beharka, 1998; Han \& Meydani, 1999); some of these studies report improved immune cell functions in the animals receiving additional vitamin E (Han \& Meydani, 1999). Vitamin E prevented the retrovirus-induced decrease in production of IL-2 and interferon- $\gamma$ (IFN- $\gamma$ ) by spleen lymphocytes and in natural killer cell activity in mice (Wang et al. 1994). In another study, young and old mice were fed diets containing adequate $(30 \mathrm{mg} / \mathrm{kg}$ diet $)$ or high $(500 \mathrm{mg} / \mathrm{kg}$ diet $)$ levels of vitamin $\mathrm{E}$ for 6 weeks and infected with influenza A virus. Young or old mice fed the high level of vitamin $\mathrm{E}$ had lower lung titres of virus than old mice fed the adequate vitamin E diet (Hayek et al. 1997). The high level of vitamin $\mathrm{E}$ caused increased production of IL-2 and IFN- $\gamma$ by spleen lymphocytes from influenza-infected old mice (Han et al. 1998). These observations suggest that increasing vitamin $\mathrm{E}$ intake above habitual levels might enhance immune function and improve resistance and that vitamin $\mathrm{E}$ supplementation might be particularly beneficial in the elderly.

Studies in man also suggest a relationship between vitamin E supply and immune function. Canadian 3-year-olds with the lowest serum vitamin E levels had the lowest lymphocyte proliferative responses and serum IgM concentrations (Vobecky et al. 1984). Chavance et al. (1989) 
found a positive association between plasma vitamin $\mathrm{E}$ levels and DTH responses, and a negative association between plasma vitamin $\mathrm{E}$ levels and incidence of infections, in healthy adults aged over sixty. Administration of vitamin $\mathrm{E}$ to premature infants enhanced neutrophil phagocytosis (Baehner et al. 1977; Chirico et al. 1983) but decreased the ability of neutrophils to kill bacteria (Baehner et al. 1977); this latter effect is most likely due to a vitamin E-induced decrease in the production of free radicals and related reactive species. Supplementation of the diet of elderly subjects with $800 \mathrm{mg}$ vitamin E/d for 4 weeks increased lymphocyte proliferation, IL-2 production and the DTH response, but did not affect IL-1 production, the number of $\mathrm{CD} 4^{+}$cells or circulating Ig concentrations (Meydani et al. 1990). In a more recent study, 60, 200 and $800 \mathrm{mg}$ vitamin E/d increased the DTH response in elderly subjects, with $200 \mathrm{mg} / \mathrm{d}$ having the maximal effect (Fig. 3; Meydani et al. 1997). The $200 \mathrm{mg} / \mathrm{d}$ dose increased the antibody responses to hepatitis B, tetanus toxoid and pneumococci vaccinations (Fig. 3; Meydani et al. 1997). In some cases the $800 \mathrm{mg}$ vitamin E/d supplement decreased the antibody response to below that of the placebo group (Fig. 3). The authors concluded that $200 \mathrm{mg}$ of vitamin E daily represents the optimal level for the immune response. Some studies report that high levels of vitamin $\mathrm{E}$ in the human diet $(>300 \mathrm{mg} / \mathrm{d})$ decrease the ability of neutrophils to undergo phagocytosis (Boxer, 1986) and to kill bacteria (Baehner et al. 1977; Prasad, 1980) and decrease monocyte respiratory burst and IL-1 $\beta$ production (Devaraj et al. 1996).

Zinc. $\mathrm{Zn}$ deficiency in animals is associated with a wide range of immune impairments (for reviews see Fraker et al. 1993; Wellinghausen et al. 1997; Shankar \& Prasad, 1998). Zn deficiency has a marked impact on bone marrow, decreasing the number of nucleated cells and the number and proportion of cells which are lymphoid precursors (for reviews see Fraker et al. 1993; Fraker \& King, 1998). In patients with $\mathrm{Zn}$ deficiency related to sickle cell disease, natural killer cell activity is decreased, but can be returned to normal by $\mathrm{Zn}$ supplementation (Tapazoglou et al. 1985). In acrodermatitis enteropathica, which is characterised by reduced intestinal $\mathrm{Zn}$ absorption, thymic atrophy, impaired lymphocyte development, decreased numbers of $\mathrm{CD} 4^{+}$cells and reduced lymphocyte responsiveness and DTH are observed (Chandra \& Dayton, 1982; Fraker et al. 1986). Moderate or mild Zn deficiency or experimental $\mathrm{Zn}$ deficiency (induced by $\mathrm{Zn}$ consumption of $<3.5 \mathrm{mg} / \mathrm{d}$; habitual intakes among adults in the UK are 9 to $12 \mathrm{mg} / \mathrm{d}$ ) in man results in decreased thymulin activity, decreased natural killer cell activity, a lowered $\mathrm{CD}^{+}: \mathrm{CD}^{+}$, and decreased lymphocyte proliferation, IL-2 production and DTH response; all can be corrected by Zn repletion (Shankar \& Prasad, 1998). Experimental Zn deficiency in man decreased IL-2, IFN- $\gamma$ and TNF- $\alpha$ production by mitogen-stimulated lymphocytes but did not affect IL-4, IL-6 or IL-10 production by these cells or IL-1 $\beta$ production by lipopolysaccharide-stimulated cells (Beck et al. 1997).

Low plasma $\mathrm{Zn}$ levels predicted the subsequent development of lower respiratory tract infections and diarrhoea among Indian infants (Bahl et al. 1988). Indeed, diarrhoea
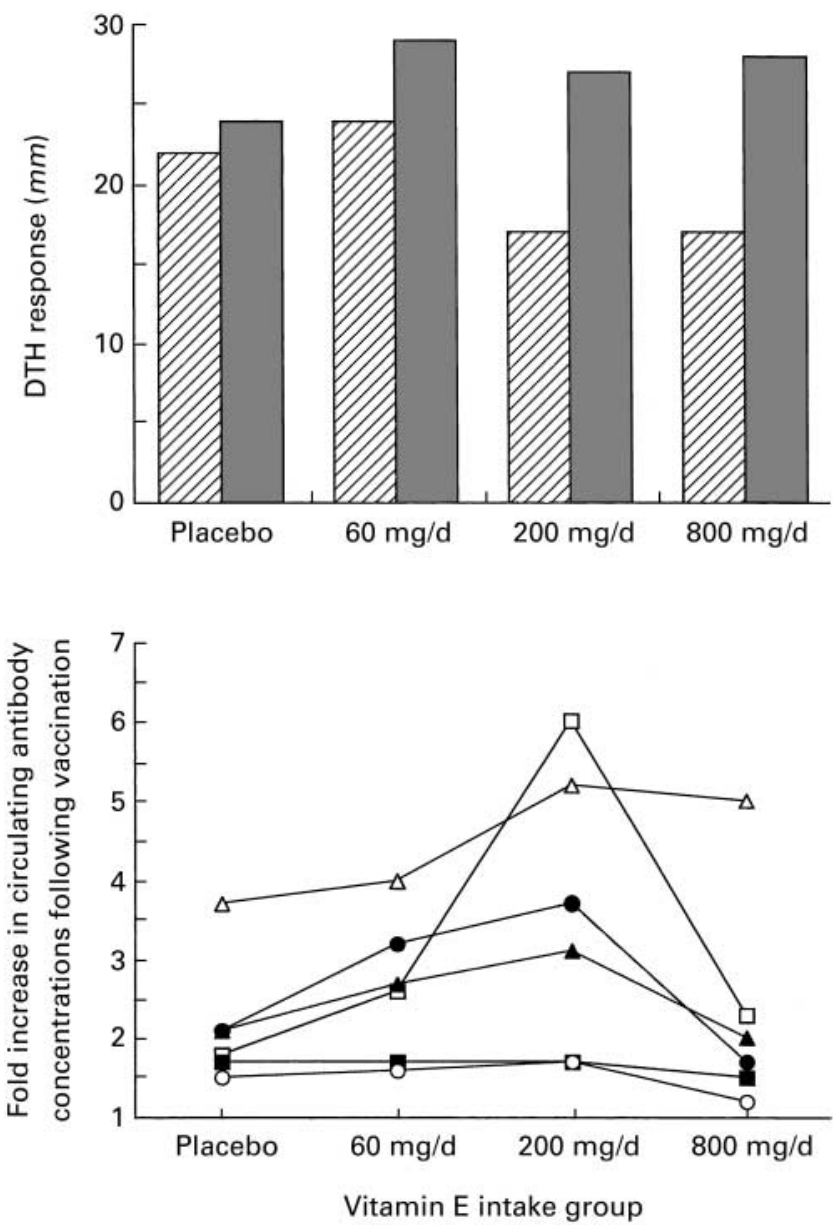

Fig. 3. Vitamin $E$ and human immune function. Healthy elderly subjects supplemented their habitual diet with a placebo or with vitamin $E$ at levels of 60,200 or $800 \mathrm{mg} / \mathrm{d}$. The delayed-type hypersensitivity (DTH) response to seven recall antigens was assessed at baseline $(\mathbb{Q})$ and after 4 months $(\square)$. Subjects were then vaccinated against hepatitis B (with subsequent boosters; $\square$ ), diphtheria ( $\square$ ), tetanus toxoid $(O)$ and three different pneumococci (PN6B (०), PN14 $(\triangle)$ and PN19F $(\Delta))$; antibodies to the vaccines were measured prior to vaccination and 3 months later. Plasma vitamin $E$ concentrations $(\mu \mathrm{M})$ after 4 months' supplementation were 23 (placebo), $38(60 \mathrm{mg} / \mathrm{d}), 51(200 \mathrm{mg} / \mathrm{d})$ and $71(800 \mathrm{mg} / \mathrm{d})$. Vitamin $E$ intakes for adults in the UK vary between 3.5 and $19.5 \mathrm{mg} / \mathrm{d}$ (men) and 2.5 and $15.2 \mathrm{mg} / \mathrm{d}$ (women). (From Meydani et al. 1997.)

is considered a symptom of $\mathrm{Zn}$ deficiency. Malnourished, $\mathrm{Zn}$-deficient children given $\mathrm{Zn}(2 \mathrm{mg} / \mathrm{kg}$ body weight daily for 10 days) had increased thymus size as judged by radiography (Golden et al. 1977). Topical application of $\mathrm{Zn}$ to malnourished children improved the DTH response in the area of skin on which the application was made (Golden et al. 1978). Zn administration ( $2 \mathrm{mg} / \mathrm{kg}$ body weight daily) to malnourished children decreased the incidence of diarrhoea by more than $50 \%$, decreased the incidence of respiratory and skin infections, and resulted in threefold increased growth compared with children given low-dose $\mathrm{Zn}$ (3.5 mg daily; Castillo-Duran et al. 1987). There are now a number of studies showing that $\mathrm{Zn}$ supplementation decreases the incidence of childhood diarrhoea and respiratory illness (for references see Scrimshaw \& SanGiovanni, 1997; Shankar \& Prasad, 1998; Calder \& 
Jackson, 2000), although some studies fail to show benefit of $\mathrm{Zn}$ supplementation in respiratory disease (for references see Calder \& Jackson, 2000). As well as decreasing the risk of young infants developing diarrhoea (Rosado et al. 1997), $\mathrm{Zn}$ supplementation $(20 \mathrm{mg} / \mathrm{d})$ to malnourished children reduced diarrhoea-induced growth faltering (Roy et al. 1999). Zn administration to preterm low-birth-weight infants $(1 \mathrm{mg} / \mathrm{kg}$ daily for 30 days increased the number of circulating $\mathrm{T}$ lymphocytes and lymphocyte proliferation (Chandra, 1991). Providing $5 \mathrm{mg} \mathrm{Zn/d} \mathrm{to} \mathrm{low-birth-weight,} \mathrm{small-for-gestational-age}$ infants for 6 months increased measures of cell-mediated immune function and decreased the incidence of gastrointestinal and upper respiratory tract infections (Lira et al. 1998); a $\mathrm{Zn}$ dose of $1 \mathrm{mg} / \mathrm{d}$ was without effect.

As observed for vitamin E, excessive $\mathrm{Zn}$ intakes impair immune responses. For example, giving $300 \mathrm{mg} \mathrm{Zn/d} \mathrm{for} 6$ weeks to young adult human subjects decreased lymphocyte and phagocyte function (Chandra, 1984). High Zn intakes can result in $\mathrm{Cu}$ depletion, and $\mathrm{Cu}$ deficiency impairs immune function (for reviews see Prohaska \& Failla, 1993; Failla \& Hopkins, 1998).

\section{Probiotics: functional food components that impact on immune function}

Indigenous bacteria are believed to contribute to the immunological protection of the host by creating a barrier against colonisation by pathogenic bacteria. This barrier can be disrupted by disease and by use of antibiotics, so allowing easier access of the host gut by pathogens. It is now believed that this barrier can be maintained by providing supplements containing live 'desirable' bacteria: such supplements are called probiotics (for extensive reviews see Goldin, 1998; Naidu et al. 1999). Probiotic organisms are found in fermented foods, including traditionally cultured dairy products and newer kinds of fermented milks. The organisms included in commercial probiotics include lactic acid bacteria (Lactobacillus acidophilus, Lactobacillus casei, Enterococcus faecium) and Bifidobacterium spp. These organisms colonise the gut only temporarily and so their regular consumption is necessary. In addition to creating a barrier effect, some of the metabolic products of probiotic bacteria (e.g. lactic acid and a class of antibiotic proteins termed bacteriocins, produced by some bacteria) may inhibit growth of pathogenic organisms (Fig. 4). Also, the desirable bacteria may compete for nutrients with the pathogens (Fig. 4). Finally, there is some evidence that probiotic bacteria may enhance the gut immune response against pathogenic bacteria (Fig. 4).

Studies in rats and mice reveal that lactic acid bacteria administered orally increase the numbers of $\mathrm{T}$ lymphocytes, $\mathrm{CD}^{+}$cells and antibody-secreting cells, including those in the intestinal mucosa, and enhance lymphocyte proliferation, natural killer cell activity, IL-1, TNF and IFN- $\gamma$ production, antibody production (including secretory $\operatorname{IgA}$ ), phagocytic activity and the respiratory burst of macrophages and the DTH response (for a review see Naidu et al. 1999). However, not all strains of lactic acid bacteria are equally effective (Naidu et al. 1999). Animal studies also show that orally administered lactic acid bacteria protect against challenges with pathogenic bacteria such as Salmonella typhimurium, reverse some of the immunosuppressive effects of malnutrition and cause the symptoms of enterocolitis to be less severe (Naidu et al. 1999). Co-colonisation of rats with

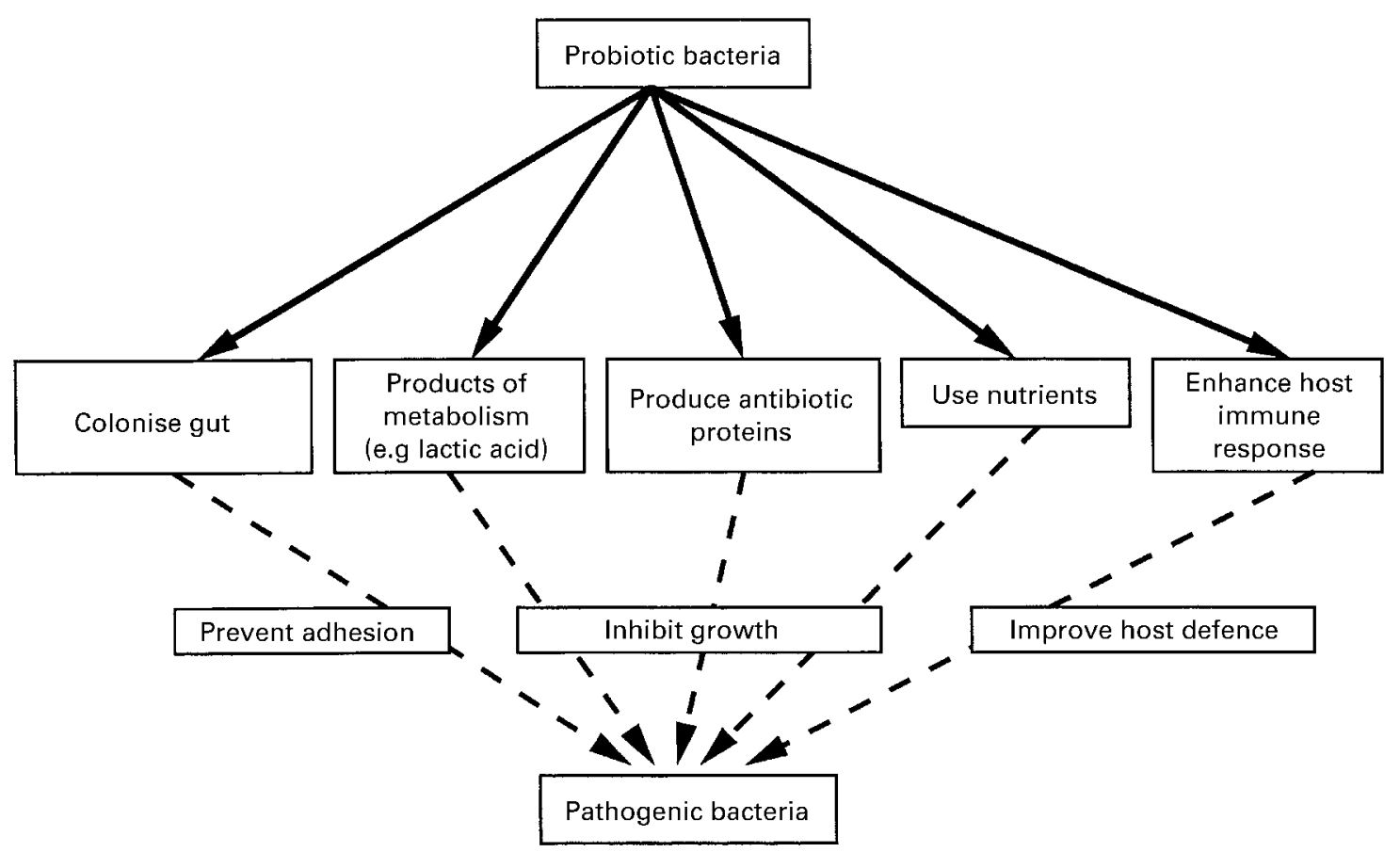

Fig. 4. Potential roles of probiotic bacteria in the human intestinal tract. Probiotic bacteria may act in a variety of ways to prevent the growth and colonisation of pathogenic bacteria. 


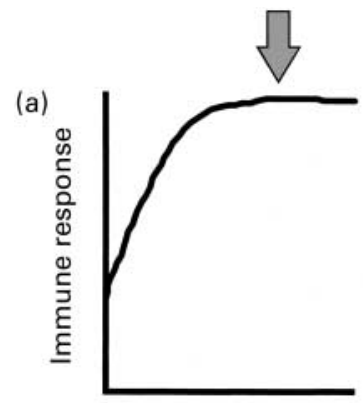

(b)

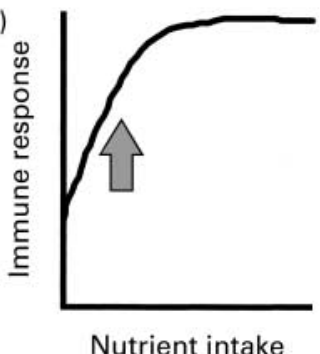

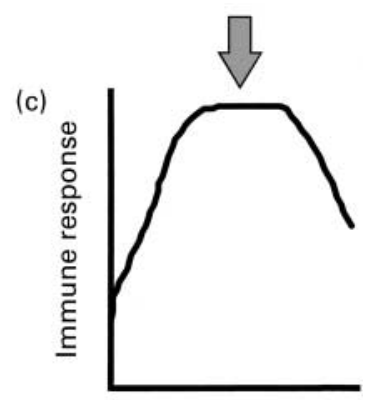

(d)

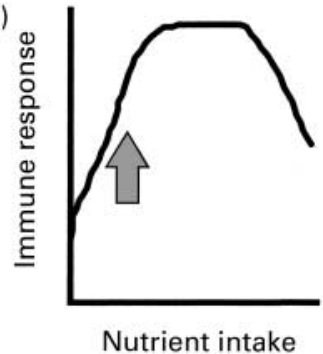

Fig. 5. Potential patterns of relationship between nutrient supply and immune function. All patterns assume that a deficiency of the nutrient impairs the immune response. In (a) the recommended intake of the nutrient is an intake at which the maximal immune response occurs and intakes somewhat above the recommended intake do not impair immune function. In (b) the recommended intake is below the intake at which the maximal immune response occurs and intakes somewhat above the recommended intake do not impair immune function. In (c) the recommended intake of the nutrient is an intake at which the maximal immune response occurs and intakes somewhat above the recommended intake impair immune function. In (d) the recommended intake is below the intake at which the maximal immune response occurs and intakes somewhat above the recommended intake impair immune function.

Lactobacillus plantarum and Escherichia coli resulted in higher circulating concentrations of total $\operatorname{IgA}$ and of $E$. coli-specific $\operatorname{IgA}$ and $\operatorname{IgM}$ than if the rats were colonised with $E$. coli alone; there was also increased expression of the IL-2 receptor in the lamina propria (Herias et al. 1999).

Despite the extensive animal studies, the effects of probiotic bacteria on human immune function are still controversial (Naidu et al. 1999). However, several studies in man have reported an enhancement in markers of immune function following probiotic administration.

Healthy Japanese children consuming a probiotic formula containing bifidobacteria had increased faecal levels of total and anti-poliovirus $\operatorname{IgA}$ than prior to taking the formula (Fukushima et al. 1998). Healthy adults consuming probiotic bacteria showed enhanced phagocytosis by neutrophils and monocytes (Schiffrin et al. 1997; Yoon et al. 1999). Adults fed fermented milk containing lactobacilli and bifidobacteria and exposed to S. typhimurium showed increased total and S. typhimuruim-specific IgA concentrations in their serum (Link-Amster et al. 1994). Administration of probiotic bacteria reduced the incidence and severity of diarrhoea in children attending daycare centres and the duration of diarrhoea in infants hospitalised with gastroenteritis; in some studies this was associated with an increase in levels of $\operatorname{IgG}, \operatorname{IgA}$ and $\operatorname{IgM}$ and in anti-rotavirus IgA secreting cells in the bloodstream (for references see Naidu et al. 1999). Probiotic bacteria have also been shown to reduce the incidence of antibioticinduced diarrhoea in children (Arvola et al. 1999; Vanderhoof et al. 1999). Although some studies have shown that consumption of probiotics can protect against traveller's diarrhoea, other studies do not demonstrate such protection (for references see Naidu et al. 1999).

\section{The immune system as a target for functional foods?}

As described earlier, deficiency of total energy or of one or more essential nutrients impairs immune function and increases susceptibility to infectious pathogens. This is most likely because these nutrients are involved in the molecular and cellular responses to challenge of the immune system. Providing these nutrients to deficient individuals restores immune function and improves resistance to infection. For some nutrients (e.g. vitamin E) the dietary intakes that result in greatest enhancement of immune function are greater than recommended intakes. However, excess intake of some nutrients (e.g. vitamin $\mathrm{E}, \mathrm{Zn}$ ) also impairs immune responses. Thus, four potential general relationships appear to exist between the intake of a nutrient and immune function (Fig. 5). These different types of relationship might in part reflect interactions between nutrients such that an excess of one nutrient negatively affects the status of a second nutrient (e.g.

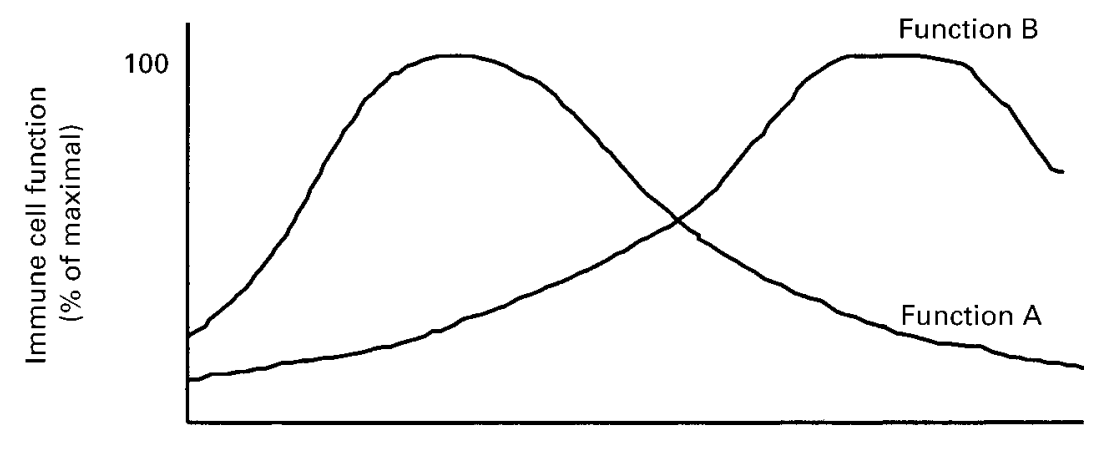

Nutrient intake

Fig. 6. Different components of the immune system may respond to intakes of a particular nutrient in different ways. 
$\mathrm{Zn}$ and $\mathrm{Cu}$ ). There are likely to be interactions between similar classes of nutrients (e.g. $n-6$ and $n-3$ polyunsaturated fatty acids) that have yet to be unravelled fully, and there are most likely interactions between nutrients which contribute to oxidative stress (e.g. polyunsaturated fatty acids) and those which protect against it (e.g. vitamin $\mathrm{E})$.

It is often assumed when defining the relationship between nutrient intake and immune function that all components of the immune system will respond in the same dose-dependent fashion to a given nutrient. This is not correct, at least as far as some nutrients are concerned, and it appears likely that different components of the immune system show an individual dose-response relationship to the availability of a given nutrient (Fig. 6). Indeed, some immune functions might be relatively insensitive to nutrient supply.

Some consider that the immune system does not respond optimally to challenge in apparently healthy, free-living human individuals even if they are not deficient in any single nutrient. Individuals may be marginally deficient in one or more nutrients or they may be consuming some nutrients (e.g. fat) in excess. There is now much interest in optimising the immune response in such individuals not simply by correcting marginal deficiencies but by increasing the intake of certain nutrients and probiotics. At this stage the immuno-enhancing effect of such supplementation is generally unproven. Indeed, as far as micronutrients are concerned, such supplementation might even be dangerous. Before the immune system can be considered a genuine target for functional foods, more needs to be known about the role of variation in the immune response among apparently healthy individuals in determining their susceptibility to infection; about the influence of altered supply of specific nutrients and of nutrient combinations on aspects of immune function in different populations; about the impact of genotype, gender, age and early life experiences on immune function and on determining the sensitivity of the immune system to nutrients; and, most importantly, about whether enhanced immune responses really translate into increased resistance to infection.

\section{Acknowledgements}

The experimental results shown in Table 1 are taken from a research project supported by the Ministry of Agriculture Fisheries and Food, the Biotechnology and Biological Sciences Research Council, Hoffmann-La Roche and Unilever Research Vlaardingen under the Agri-Food LINK Program (Grant Number AFQ111). The authors are indebted to Miss T. Banerjee and to collaborators at the Hugh Sinclair Unit of Human Nutrition, School of Food Biosciences, University of Reading for their role in this research.

\section{References}

Arvola T, Laiho K, Torkkeli S, Mykkanen H, Salminen S,
Maunula L \& Isolauri E (1999) Prophylactic Lactobacillus GG reduces antibiotic-associated diarrhea in children with respiratory infections: a randomised study. Pediatrics 104, L1-L4.

Baehner RL, Boxer LA, Allen JM \& Davis J (1977) Autooxidation as a basis for altered function by polymorphonuclear leukocytes. Blood 50, 327-335.

Bahl R, Bhandari N, Hambridge KM \& Bhan MK (1988) Plasma zinc as a predictor of diarrhoeal and respiratory morbidity in children in an urban slum setting. American Journal of Clinical Nutrition 68, 414S-417S.

Beach RS, Gershwin ME \& Hurley LS (1982) Gestational zinc deprivation in mice: persistence of immunodeficiency for three generations. Science 218, 469-471.

Beck FWJ, Prasad AS, Kaplan J, Fitzgeral JT \& Brewer GJ (1997) Changes in cytokine production and T cell subpopulations in experimentally induced zinc deficient humans. American Journal of Physiology 272, E1002-E1007.

Bendich A (1993) Vitamin E and human immune functions. In Nutrition and Immunology, pp. 217-228 [DM Klurfeld, editor]. New York/London: Plenum Press.

Boxer LA (1986) Regulation of phagocyte function by $\alpha$-tocopherol. Proceedings of the Nutrition Society 45, 333-344.

Calder PC \& Jackson AA (2000) Undernutrition, infection and immune function. Nutrition Research Reviews 13, 3-29.

Calder PC \& Yaqoob P (2000) The level of protein and type of fat in the diet of pregnant rats both affect lymphocyte function in the offspring. Nutrition Research 20, 995-1005.

Castillo-Duran C, Heresi G, Fisberg M \& Uauy R (1987) Controlled trial of zinc supplementation during recovery from malnutrition: effects on growth and immune function. American Journal of Clinical Nutrition 45, 602-608.

Chandra RK (1984) Excessive intake of zinc impairs immune responses. Journal of the American Medical Association 252, $1443-1446$.

Chandra RK (1991) 1990 McCollum Award Lecture. Nutrition and immunity: lessons from the past and new insights into the future. American Journal of Clinical Nutrition 53, 1087-1101.

Chandra RK \& Dayton DH (1982) Trace element regulation of immunity and infection. Nutrition Research 2, 721-733.

Chavance M, Herbeth B, Fournier C, Janot C \& Vernhes G (1989) Vitamin status, immunity and infections in an elderly population. European Journal of Clinical Nutrition 43, 827-835.

Chirico G, Marconi M, Colombo A, Chiara A, Rondini G \& Ugazio A (1983) Deficiency of neutrophil phagocytosis in premature infants: effect of vitamin E supplementation. Acta Pediatrica Scandanavica 72, 521-524.

Corwin LM \& Schloss J (1980) Role of antioxidants on the stimulation of the mitogen response. Journal of Nutrition 110, 2497-2505.

Cunningham-Rundles S (1998) Analytical methods for evaluation of immune response in nutrient intervention. Nutrition Reviews 56, S27-S37.

Devaraj S, Li D \& Jialal I (1996) The effects of $\alpha$-tocopherol supplementation on monocyte function. Journal of Clinical Investigation 98, 756-763.

Failla ML \& Hopkins RG (1998) Is low copper status immunosuppressive? Nutrition Reviews 56, S59-S64.

Fraker PJ, Gershwin ME, Good RA \& Prasad A (1986) Interrelationships between zinc and immune function. Federation Proceedings 45, 1474-1479.

Fraker P \& King L (1998) Changes in regulation of lymphpoiesis and myelopoiesis in the zinc-deficient mouse. Nutrition Reviews 56, S65-S69.

Fraker PJ, King LE, Garvy BA \& Medina CA (1993) The immunopathology of zinc deficiency in humans and rodents: 
a possible role for programmed cell death. In Nutrition and Immunology, pp. 267-283 [DM Klurfeld, editor]. New York/ London: Plenum Press.

Fukushima Y, Kawata Y, Hara H, Terada A \& Mitsuoka T (1998) Effect of probiotic formula on intestinal immunoglobulin A production in healthy children. International Journal of Food Microbiology 42, 39-44.

Golden MHN, Golden BE, Harland PSEG \& Jackson AA (1978) Zinc and immunocompetence in protein-energy malnutrition. Lancet i, 1226-1228.

Golden MHN, Jackson AA \& Golden BE (1977) Effect of zinc on thymus of recently malnourished children. Lancet ii, 1057-1059.

Goldin BR (1998) Health benefits of probiotics. British Journal of Nutrition 80, S203-S207.

Gross RL \& Newberne PM (1980) Role of nutrition in immunologic function. Physiological Reviews 60, 188-302.

Han SN \& Meydani SN (1999) Vitamin E and infectious disease in the aged. Proceedings of the Nutrition Society 58, 697-705.

Han SN, Wu D, Smith DE, Beharka A, Wang H, Bender BS \& Meydani SN (1998) Vitamin E supplementation increases splenocyte IL-2 and IFN- $\gamma$ production in old mice infected with influenza virus. FASEB Journal 12, A819.

Hayek MG, Taylor SF, Bender BS, Han SN, Meydani M, Smith DE, Eghtesada S \& Meydani SN (1997) Vitamin E supplementation decreases lung virus titers in mice infected with influenza. Journal of Infectious Diseases 176, 273-276.

Herias MV, Hessle C, Telemo E, Midtvedt T, Hanson LA \& Wold AE (1999) Immunomodulatory effects of Lactobacillus plantarum colonizing the intestine of gnotobiotic rats. Clinical and Experimental Immunology 116, 283-290.

Kuvibidila S, Yu L, Ode D \& Warrier RP (1993) The immune response in protein-energy malnutrition and single nutrient deficiencies. In Nutrition and Immunology, pp. 121-155 [DM Klurfeld, editor]. New York/London: Plenum Press.

Link-Amster H, Rochat F, Saudan KY, Mignot O \& Aeschlimann JM (1994) Modulation of a specific humoral immune response and changes in intestinal flora mediated through fermented milk intake. FEMS Immunology and Medical Microbiology 10, 55-64.

Lira PI, Ashworth A \& Morris SS (1998) Effect of zinc supplementation on the morbidity, immune function and growth of low birth weight full-term infants in northeast Brazil. American Journal of Clinical Nutrition 69, 418S-424S.

McDade TW, Beck MA, Kuzawa C \& Adair SS (2001) Prenatal undernutrition, postnatal environments, and antibody response to vaccination in adolescence. American Journal of Clinical Nutrition 74, 543-548.

Meydani SN, Barklund MP, Liu S, Meydani M, Miller RA, Cannon JG, Morrow FD, Rocklin R \& Blumberg JB (1990) Vitamin E supplementation enhances cell-mediated immunity in healthy elderly subjects. American Journal of Clinical Nutrition 52, 557-563.

Meydani SN \& Beharka AA (1998) Recent developments in vitamin $\mathrm{E}$ and immune response. Nutrition Reviews 56, S49-S58.

Meydani SN, Endres S, Woods MM, Goldin BR, Soo C, MorrillLabrode A, Dinarello C \& Gorbach SL (1991) Oral $(n-3)$ fatty acid supplementation suppresses cytokine production and lymphocyte proliferation: comparison between young and older women. Journal of Nutrition 121, 547-555.

Meydani SN, Meydani M, Blumberg JB, Leka LS, Siber G, Loszewski R, Thompson C, Pedrosa MC, Diamond RD \& Stollar BD (1997) Vitamin E supplementation and in vivo immune response in healthy subjects. Journal of the American Medical Association 277, 1380-1386.

Meydani SN, Meydani M, Verdon CP, Shapiro AC, Blumberg JB
\& Hayes KC (1986) Vitamin E supplementation suppresses prostaglandin E2 synthesis and enhances the immune response in aged mice. Mechanisms of Ageing and Development 34, 191-201.

Meydani SN, Yogeeswaran G, Liu S, Baskar S \& Meydani M (1988) Fish oil and tocopherol-induced changes in natural killer cell-mediated cytotoxicity and $\mathrm{PGE}_{2}$ synthesis in old and young mice. Journal of Nutrition 118, 1245-1252.

Moore SE, Cole TJ, Poskitt EME, Sonko BJ, Whitehead RG, McGregor IA \& Prentice AM (1997) Season of birth predicts mortality in rural Gambia. Nature 338, 434.

Naidu AS, Bidlack WR \& Clemens RA (1999) Probiotic spectra of lactic acid bacteria (LAB). Critical Reviews in Food Science and Nutrition 38, 13-126.

Prasad JS (1980) Effect of vitamin E supplementation on leukocyte function. American Journal of Clinical Nutrition 33, 606-608.

Prohaska JR \& Failla ML (1993) Copper and immunity. In Nutrition and Immunology, pp. 309-332 [DM Klurfeld, editor]. New York/London: Plenum Press.

Rayon JI, Carver JD, Wyble LE, Wiener D, Dickey SS, Benford VJ, Chen LT \& Lim DV (1997) The fatty acid composition of maternal diet affects lung prostaglandin E2 levels and survival from Group B Streptococcal sepsis in neonatal rat pups. Journal of Nutrition 127, 1989-1992.

Rosado JL, Lopez P, Munoz E, Martinez H \& Allen LH (1997) Zinc supplementation reduced morbidity, but neither zinc nor iron supplementation affected growth or body composition of Mexican pre-schoolers. American Journal of Clinical Nutrition 65, $13-19$.

Roy SK, Tomkins AM, Haider R, Behra RH, Akramuzzaman SM, Mahalanabis D \& Fuchs GJ (1999) Impact of zinc supplementation on subsequent growth and morbidity in Bangladeshi children with acute diarrhoea. European Journal of Clinical Nutrition 53, 529-534.

Schiffrin EJ, Brassart D, Servin AL, Rochat F \& Donnet-Hughes A (1997) Immune modulation of blood leukocytes in humans by lactic acid bacteria: criteria for strain selection. American Journal of Clinical Nutrition 66, S515-S520.

Scrimshaw NS \& SanGiovanni JP (1997) Synergism of nutrition, infection and immunity: an overview. American Journal of Clinical Nutrition 66, 464S-477S.

Shankar AH \& Prasad AS (1998) Zinc and immune function: the biological basis of altered resistance to infection. American Journal of Clinical Nutrition 68, 447S-463S.

Tapazoglou E, Prasad AS, Hill G, Brewer GJ \& Kaplan J (1985) Decreased natural killer cell activity in patients with zinc deficiency and sickle cell disease. Journal of Laboratory and Clinical Medicine 15, 19-22.

Thies F, Miles EA, Nebe-von-Caron G, Powell JR, Hurst TL, Newsholme EA \& Calder PC (2001a) Influence of dietary supplementation with long chain $n-3$ or $n-6$ polyunsaturated fatty acids on blood inflammatory cell populations and functions and on plasma soluble adhesion molecules in healthy adults. Lipids 36, 1183-1193.

Thies F, Nebe-von-Caron G, Powell JR, Yaqoob P, Newsholme EA \& Calder PC (2001b) Dietary supplementation with $\gamma$-linolenic acid or fish oil decreases T lymphocyte proliferation in healthy older humans. Journal of Nutrition $\mathbf{1 3 1}$ 1918-1927.

Vanderhoof JA, Whitney DB, Antonson DL, Hanner TL, Lupo JV \& Young RJ (1999) Lactobacillus GG in the prevention of antibiotic-associated diarrhea in children. Journal of Pediatrics 135, 564-568.

Vobecky JS, Vobecky J, Shapcott D \& Rola-Pleszczynski M (1984) Nutritional influences on humoral and cell-mediated immunity in healthy infants. Journal of the American College of Nutrition 3, 265 
Wang Y, Huang DS, Eskelson CD \& Watson RR (1994) Long-term dietary vitamin $\mathrm{E}$ retards development of retrovirus-induced dysregulation in cytokine production. Clinical Immunology and Immunopathology 72, 70-75.

Wellinghausen N, Kirchner H \& Rink L (1997) The immunobiology of zinc. Immunology Today 18, 519-521.

Yaqoob P, Newsholme EA \& Calder PC (1999) Comparison of cytokine production in cultures of whole human blood and purified mononuclear cells. Cytokine 11, 600-605.

Yaqoob P, Pala HS, Cortina-Borja M, Newsholme EA \& Calder PC (2000) Encapsulated fish oil enriched in $\alpha$ - tocopherol alters plasma phospholipid and mononuclear cell fatty acid compositions but not mononuclear cell functions. European Journal of Clinical Investigation 30, 260-274.

Yoon H, Dubarry M, Bouley C, Meredith C, Portier A, Tome D, Renevot O, Blachon JL, Dugas B, Drewitt P \& Postaire E (1999) New insights in the validation of systemic biomarkers for the evaluation of the immunoregulatory properties of milk fermented with yoghurt culture and Lactobacillus casei (Actimel $(\mathrm{R})$ ): a prospective trial. International Journal of Immunotherapy 15, 79-89. 